confirmed every day or every second day appropriate use of the color-in puppet and spaces for parents and teachers. Experienced applicability: Identified themes were: child-friendly, easy and providing a clear guide for the daily school situation. Themes as: daily obligation, unwillingness of the child, lack of motivation or time of the parents or teachers and insufficient instruction illustrated experienced barriers for the use of the booklet. Effectiveness: Identified themes: 1) Children express themselves better about feelings of pain and fatigue, 2) Parents and teachers appreciate more insight into how the child feels and 3)Teachers feel provided with guidance in the interaction with the child 4) Children feel more secure to express itself at school and 4) Parents are more relaxed about the schoolsituation.

Likertscales showed that more than $75 \%$ of the users would advise the B\&FS to other parents, teachers and therapists.

Conclusion: The Back \& Forth School booklet is a feasible shared management instrument to support young children with JIA in the school situation. A less rigid daily routine and sufficient instruction can improve the experienced applicability. References:

[1] Tong, A. Children's experiences of living with juvenile idiopathic arthritis. Arthritis Care Res. 2012;64(9):1392-1404.

[2] Kieckhefer, G Supporting development of children with chronic conditions: from compliance toward Shared management. Pediatr Nursing, 2000;26(4).
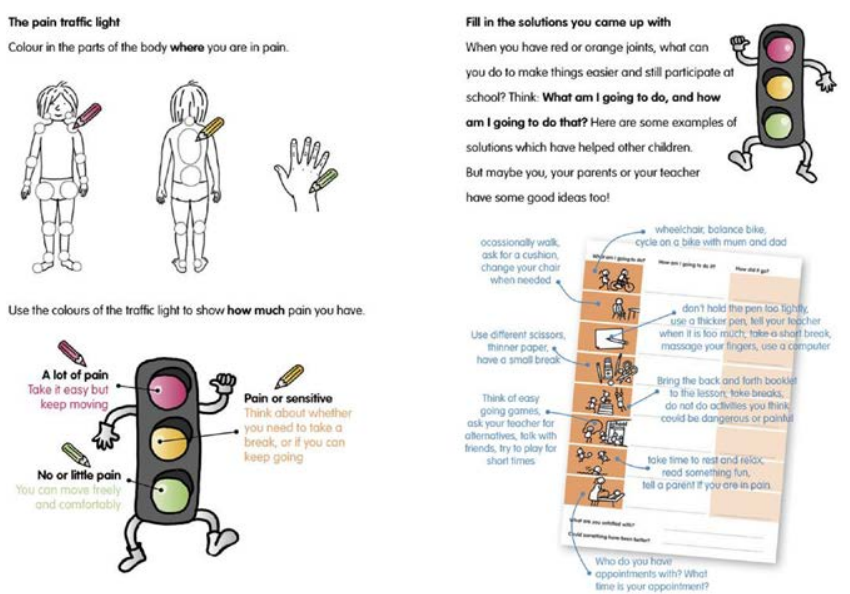

Figure 1 Educational page: Pain management



Figure 2 Diary page

Acknowledgments: Children, parents, teachers and therapists Disclosure of Interests: None declared DOI: 10.1136/annrheumdis-2020-eular.4950

\section{AB1342-HPR RHEUMATOLOGY 'HOT CLINIC' IN A TEACHING HOSPITAL - WHAT CAN BE EXPECTED?}

M. Chakravorty ${ }^{1}$, J. Southern ${ }^{1}$, L. H. Lee ${ }^{2} .{ }^{1}$ Royal Derby Hospital, Rheumatology, Derby, United Kingdom; ${ }^{1}$ Royal Derby Hospital, Rheumatology, Derby, United Kingdom
Background: Increased financial and bed pressures faced by the NHS have necessitated significant changes in the service provision of many inpatient medical specialties. At the Royal Derby Hospital, rheumatology has become predominantly outpatient-based and no longer has an allocated ward for inpatients. As a result, weekly rheumatology 'hot clinic' have been set up to help facilitate early hospital discharge and specialist outpatient review of patients with suspected rheumatological conditions. It was anticipated that the bulk of referrals would be for conditions requiring early intervention such as suspected giant cell arteritis (GCA) and hot swollen joints. However, there is a paucity of literature on the usefulness of such 'hot clinics' and the quality of referrals.

Objectives: This study sought to evaluate the range of conditions referred to the 'hot clinic' and early outcomes related to follow up or discharge.

Methods: The details of patients who attended the 'hot clinic' were retrospectively obtained using the hospital's electronic clinic appointments system. Electronic letters and discharge summaries were reviewed to determine the patient's presenting symptoms, suspected diagnosis and clinical outcome.

Results: A total of 40 patients who attended the 'hot clinic' from September 2018 to June 2019 were included. The average time from discharge to 'hot clinic' was 3.8 days (range $0-22$ days). 27 patients $(67.5 \%$ ) were seen within 7 days of hospital discharge and 2 patients were seen after 18 and 22 days respectively, which spanned over the Christmas and New Year period.

$87.5 \%$ (35) of patients were referred by acute medicine via the ambulatory care ward; $10 \%$ (4) by the Emergency Department and 1 by the medical ward. 5 patients were already known to rheumatology ( 3 with rheumatoid arthritis and 2 with psoriatic arthritis).

$37.5 \%$ of referrals were made for suspected GCA, $35 \%$ for rash and possible connective tissue disease (CTD) or vasculitis except for GCA, 20\% for swollen joints, and $7.5 \%$ for unexplained arthralgia or myalgia.

For the patients with suspected GCA, 3 out of 15 were treated as GCA after 'hot clinic' review - 2 of these went on to have a temporal artery biopsy and 1 had a positive biopsy for GCA. (All 3 received high dose steroids prior to their clinic appointment). 10 patients were felt to have an atypical headache and 3 of these were referred to neurology for further assessment. The remaining 2 patients were diagnosed with a sinus infection and migraine respectively.

Of the 14 patients referred with a rash and possible CTD or vasculitis except for GCA, 2 patients referred with a rash were diagnosed to have $\operatorname{IgA}$ vasculitis and referred to dermatology for further management. 2 patients were diagnosed with lupus and were followed up in the CTD clinic. 7 patients were felt to have a self-limiting post-viral or non-specific rash, 2 patients with possible drug-related rash and 1 patient thought to have erythema nodosum.

2 patients with swollen joints had a new diagnosis of seronegative inflammatory arthritis and 2 others were diagnosed with gout. 1 patient was diagnosed with osteoarthritis and another with post-viral arthritis and both were discharged. The 3 patients with unexplained arthralgia or myalgia were felt to have self-limiting post-viral illnesses and were also discharged.

Conclusion: Suspected GCA is the most common referral to the rheumatology 'hot clinic. However, the vast majority of these referrals turned out not to be GCA. The results of this study clearly suggest the need for development of better pathways e.g. for GCA and joint dermatology and rheumatology clinics.

Disclosure of Interests: None declared

DOI: 10.1136/annrheumdis-2020-eular.3956

\section{AB1343-HPR A QUALITATIVE REVIEW ASSESSING THEMATIC OUTCOMES FROM THE PHARMACY-LED ADALIMUMAB BIOSIMILAR SWITCH PLAN ACROSS 3 SPECIALITIES; RHEUMATOLOGY, GASTROENTEROLOGY AND DERMATOLOGY AT UNIVERSITY HOSPITALS OF COVENTRY AND WARWICKSHIRE (UHCW)}

S. Gohil ${ }^{1}{ }^{1}$ University Hospitals of Coventry and Warwickshire, Pharmacy, Coventry, United Kingdom

Background: The advent of biosimilars has heralded a new era for cost effective biologic prescribing in the NHS. As patents expire for originator biologics, less expensive versions are now widely available as biosimilars. Non-medical switches (for reasons unrelated to a patient's health) ensure prescribing of best value medicines, and cost savings can be redirected to patient care. ${ }^{1}$ This practice resonates with recommendations from Lord Carter's 2016 report regarding reducing unwarranted variation in the NHS and adopting cost saving opportunities. $^{2}$ In 2018/19, following loss of patent exclusivity for the expensive adalimumab originator biologic, UHCW worked in accordance with national directives to drive forward one of the largest non-medical biosimilar switches.

Objectives: This qualitative review aims to explore the success of the adalimumab biosimilar switch and key themes associated with switch backs/refusals across the Rheumatology (R), Gastroenterology (G) and Dermatology (D) specialities at UHCW. 